\title{
Aplikasi Kamus Bahasa Daerah Pasan Berbasis Android
}

\author{
Lady O. Kasema ${ }^{1)}$, Steven R. Sentinuwo ${ }^{2)}$, Alwin M. Sambul ${ }^{3)}$ \\ Program StudiTeknik Informatika, Fakultas Teknik, Universitas Sam Ratulangi \\ Ladyokasema@gmail.com, Steven@unsrat.ac.id, asambul@unsrat.ac.id
}

\begin{abstract}
Android merupakan sebuah sistem yang bersifat open source yaitu memberikan kebebasan bagi developer dalam mengembangkan sebuah aplikasi. Dengan kelebihan dari sitem operasi Android akan banyak membantu pengguna smartphone berbasis Android untuk menggunakan aplikasi. Salah satu aplikasi tersebut adalah Kamus Bahasa Daerah Pasan ini. Tujuan utama Aplikasi kamus Bahasa Daerah Pasan ini dikembangkan untuk mempermudah masyarakat dalam mencari terjemahan kata dalam bahasa Indonesia - bahasa Pasan atau sebaliknya secara efektif dan efisien. Adapun jenis data yang digunakan adalah jenis data sekunder dimana data diperoleh dari buku referensi dan literatur yang berhubungan dengan tugas akhir ini. Aplikasi ini menggunakan metode RAD (Rapid Aplication Development) yang terdiri dari empat fase dalam pengerjaan yaitu fase analisis persyaratan, fase analisis modeling, fase desain modeling dan fase konstruksi sebagai panduan langkah proses. Aplikasi ini dikembangkan menggunkan database SQLite dan bahasa pemrograman Java serta menggunakan diagram UML sebagai desain modeling aplikasi.
\end{abstract}

Kata Kunci : Android, Bahasa Indonesia, Bahasa Pasan, Kamus, metode Rapid Aplication Development.

Android is a system that is open source which provides freedom for developers in developing an application. With the advantages of the Android operating system, it will help many Android-based smartphone users to use the application. One such application is the Pasan Regional Language Dictionary. The main objective of the Pasan Regional Language Dictionary application is to facilitate the public in searching for translations of Indonesian-language Pasan or vice versa in an efficient and efficient manner. The type of data used is the type of secondary data where data is obtained from reference books and literature related to this final project. This application uses the RAD (Rapid Application Development) method which consists of four phases in workmanship, namely the requirements analysis phase, the modeling analysis phase, the modeling design phase and the construction phase as a process step guide. This application was developed using SQLite databases and the Java programming language and using UML diagrams as application modeling design .

Keywords: Android, Pasan Language, Indonesian Language, Dictionary Rapid Application Development method

\section{PENDAHULUAN}

Indonesia merupakan negara kepulauan yang memiliki suku bangsa, budaya, dan bahasa. Kita memiliki bahasa pemersatu bangsa yaitu bahasa Indonesia. Setiap daerah mempunyai bahasa yag berbeda-beda yang digunakan sebagai media komunikasi. Penggunaan bahasa daerah telah mengalami penurunan penggunaan dalam bahasa komunikasi sehari-hari. Ratahan berada dikabupaten Minahasa tenggara, yang merupakan ibu kota kabupaten ini memiliki bahasa khas yaitu bahasa Ratahan (Pasan). Sekarang ini sebagian besar dari masyarakat Ratahan sudah tidak lagi mengenal bahasa daerah ratahan, dikarenakan masyarakat sendiri menggunakan Bahasa Indonesia dalam percakapan sehari-hari

Kehidupan manusia pada masa ini tidak terlepas dari teknologi. Apapun profesinya, teknologi senantiasa memiliki peran penting dalam era globalisasi, salah satunya Teknologi komunikasi. Dengan berkembangnya teknologi saat ini dibutuhkan sebuah aplikasi yang dapat membantu pancarian kosakata sebagai pengganti buku atau kamus yang berukuran cukup tebal yang dapat dibawa kemanapun dan kapanpun. Peran kamus sangatlah penting karena kamus merupakan salah satu dari sumber ilmu yang sangat bermanfaat bagi pembelajaran manusia, didalam kamus terdapat kata-kata yang belum pernah kita ketahui.

Sekarang ini banyak kamus yang beredar, mulai dari bentuk buku, kamus elektronik, aplikasi kamus berbasis desktop, web, dan android. Kamus elektronik yang dulu berbentuk seperti kalkulator, saat ini berkembang menjadi aplikasi kamus yang ada di smartphone seperti aplikasi kamus bahasa inggris, aplikasi kamus bahasa jawa, aplikasi kamus bahasa Jerman, dan aplikasi kamus bahasa lainnya. Pemakaian aplikasi kamus pada smartphone lebih efektif digunakan mudah untuk dibawa kemanapun tanpa memerlukan tempat namun sudah tersedia didalam smartphone.

Dengan perkembangan teknologi sekarang ini munculah ide untuk membuat sebuah aplikasi sederhana yang edukatif sebagai sarana pembelajaran bahasa yaitu kamus Bahasa Ratahan (Pasan) - Indonesia dan sebaliknya berbasis android.

A. Kamus

Menurut kamus besar bahasa Indonesia, pengertian dari kamus adalah buku acuan yang memuat kata dan ungkapan yang biasanya disusun menurut abjad berikut keterangan tentang maknanya, pemakaianya dan terjemahannya, kamus juga dapat digunakan sebagai buku rujukan yang menerangkan makna katakata yang berfungsi untuk membantu seseorang mengenal perkataan baru. Selain menerangkan maksud kata, kamus juga mungkin mempunyai pedoman sebutan, asal-usul (etimologi) sesuatu perkataan dan juga contoh pernggunaan bagi sesuatu perkataan. Untuk memperjelas kadang kala terdapat juga ilustrasi di dalam kamus. Terdapat banya kamus yang populer di Indonesia seperti : kamus bahasa Inggris, bahasa Jerman, bahasa Mandarin, bahasa Jepang dan lain sebagainya

\section{B. Aplikasi}


Aplikasi dapat diartikan sebagai suatu program berbentuk perangkat lunak yang berjalan pada suatu sistem tertentu yang berguna untuk membantu berbagai kegiatan yang dilakukan oleh manusia. Selain pengertian di atas, ada banyak pengertian dari kata 'Aplikasi' yang dikemukakan oleh para ahli.

\section{C. $\quad$ Android}

Android adalah sebuah sistem operasi mobile yang berbasiskan pada versi modifikasi dari linux. Pertama kali sistem operasi ini dikembangkan oleh perusahaan android.inc, dengan dukungan finansial dari google, yang kemudian membelinya pada tahun 2005. Sistem operasi ini dirilis secara resmi pada tahun 2007, bersamaan dengan didirikannya Open Handset Alliance, konsorsium dari perusahaan-perusahaan perangkat keras, perangkat lunak, dan telekomunikasi yang bertujuan untuk memajukan standar terbuka seluler.

\section{Android Studio}

Android studio adalah IDE (Integrate Development Environment) resmi untuk pengembang aplikasi Android dan bersifat open source atau gratis, peluncuran Android Studio ini diumumkan oleh Google pada 16 mei 2013 pada event Google I/O Conference untuk tahun 2013. Sejak saat itu, Android studio mengantikan Eclipse sebagai IDE resmi untuk mengembangkan aplikasi Android.

\section{E. Java}

Java merupakan bahasa pemrograman berorientasi objek yang dapat digunakan untuk membuat dan menjalankan perangkat lunak pada komputer dan berbagai platform. Java memiliki sifat multiplatform, yang artinya java dapat dijalankan diberbagai jenis platform asalkan Java Virtual Machine sudah terinstal pada platform tersebut. jika program yang dibuat pada platform window, maka program tersebut juga dapat dijalankan pada linux, unix, dan lain-lain.

\section{F. SQLite}

SQLite adalah database Open Source yang tertanam ke Android. SQLite mendukung fitur database relasional standar seperti sintaks SQL, transaksi dan pernyataan siap. Selain itu hanya memerlukan sedikit memori pada saat runtime (sekitar 250 KByte). SQLite mendukung tipe data TEXT (mirip ke String di Jawa), INTEGER (mirip dengan yang lama di Jawa) dan REAL (mirip dengan ganda di Java). Semua jenis lain harus dikonversi ke pada bidang ini sebelum menyimpannya dalam database. SQLite sendiri tidak memvalidasi jika jenis ditulis untuk kolom sebenarnya dari jenis didefinisikan, Anda dapat menulis sebuah integer ke dalam kolom string.

\section{G. Pengertian UML}

UML ( Unified Modeling Language) adalah bahasa pemodelan untuk sistem atau perangkat lunak yang berparadigma berorientasi objek. UML ini berfungsi membantu para developer untuk menggambarkan alur dari sebuah sistem yang akan dibangun, gambaran mengenai alur sistem tersebut akan terwakili oleh simbol-simbol yang ada dalam diagramdiagaram.
H. Rapid Application Development (RAD)

Rapid Application Development (RAD) merupakan salah satu metode pengembangan suatu sistem informasi dengan waktu yang relative singkat. Untuk pengembangan suatu sistem informasi yang normal membutuhkan waktu minimal 180 hari, akan tetapi dengan menggunakan RAD suatu sistem dapat diselesaikan hanya dalam waktu 30 - 90nhari. RAD juga merupakan sebuah strategi pengembangan sistem dimana menekan kecepatan pengembangan melalui keterlibatan user ekstensif dalam kecepatan, iterative (berulang) dan incremental construction dan serangkaian fungsi dari prototype sebuah sistem yang pada akhirnya akan menglami perubahan secara bertahap menuju sistem akhir.

\section{METODOLOGI PENELITIAN}

\section{A. Objek Penelitian}

Adapun penelitian ini dilakukan untuk menyusun Tugas Akhir yang dilaksanakan berdasarkan studi literatur dan mengambil lokasi studi kasus di Wawali Pasan, Ratahan, Minahasa Tenggara.

\section{B. Metode Pengumpulan Data}

1) Studi Pustaka

Merupakan metode yang dilakukan dengan cara mencari bahan yang mendukung dalam penulisan masalah melalui bukubuku atau jurnal yang erat kaitannya dengan objek permasalahanya.

\section{2) Wawancara}

Merupakan metode yang dilakukan dengan cara melakukan diskusi serta tanya jawab dengan masyarakat setempat yang dianggap memiliki pengetahuan lebih mengenai permasalahan yang dijadikan objek penelitian.

\section{3) Dokumen}

Merupakan metode yang dilakukan dengan cara pengambilan data melalui dokumen tertulis maupun elektronik dari lembaga/institusi tempat penelitian dimana dokumen tersebut dibutuhkan untuk kelengkapan penelitian.

\section{Metode Pengembangan Aplikasi}

Perancangan dan pengembangan aplikasi Kamus Bahasa Daerah Ratahan - Indonesia berbasis Android ini menggunakan metode pengembangan Rapid Aplication Development atau rapid prototyping yang merupakan model proses pembangunan perangkat lunak yang tergolong dalam teknik incremental (bertingkat).

\section{Fase Analisis Persyaratan}

Fase ini merupakan proses pengumpulan data atau bahan dan mengidentifikasi layanan batasan atau obyektivitas dari pengumpulan data yang dilakukan.

\section{E. Fase Analisis Modeling}

Fase ini bertujuan untuk menganalisis semua kegiatan arsitektur sistem secara keseluruhan. Rencana kerja ini bertujuan 
untuk membuat Aplikasi Kamus Bahasa Daerah Pasan dengan 4 tahapan kerja yaitu : Analisis perancangan, analisis modeling, design modeling, konstruksi.

\section{Aplikasi Kamus Bahasa Daerah Pasan}

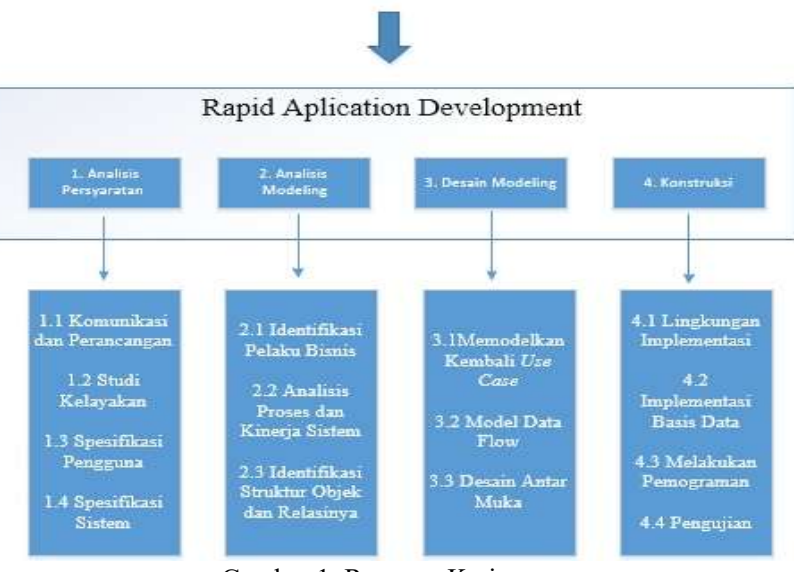

Gambar 1. Rencana Kerja

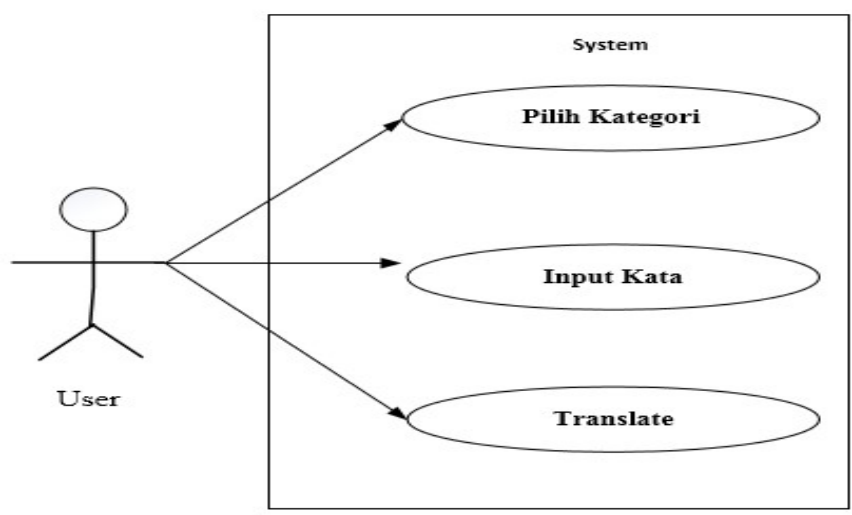

Gambar 2. Usecase Diagram User

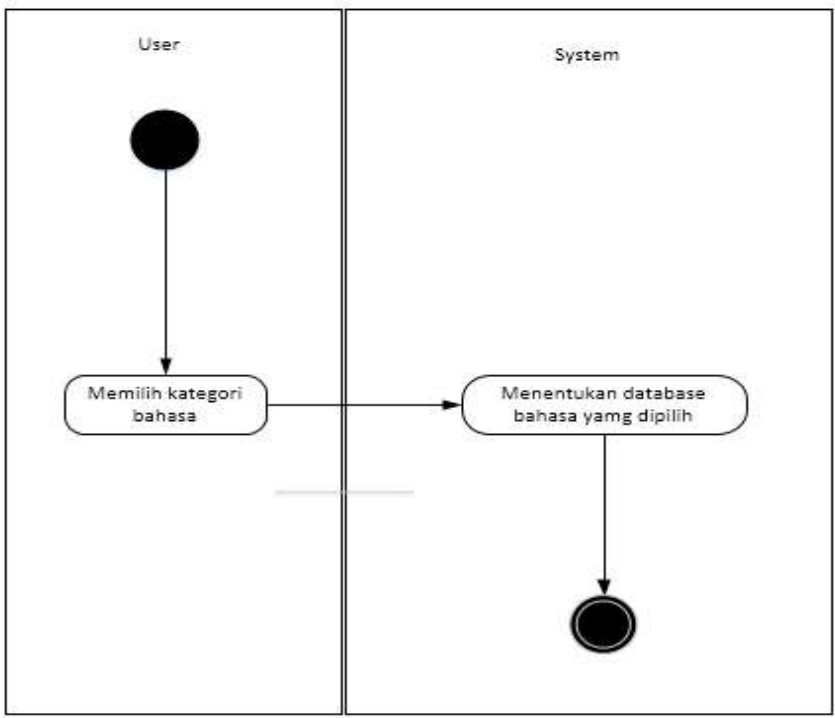

Gambar 3. Gambar activity diagram-pilih kategori
TABEL 1. AKTOR BESERTA TUGAS

\begin{tabular}{ll}
\hline \hline Aktor & \multicolumn{2}{c}{ Tugasa dan Tanggung } \\
Jawab \\
\hline User & Setiap individu yang \\
& merupakan pengguna dari \\
& aplikasi kamus Ratahan - \\
& Indonesia berbasis android \\
& untuk mencari data bahasa dan \\
& melihat terjemahan data. \\
\hline \hline
\end{tabular}

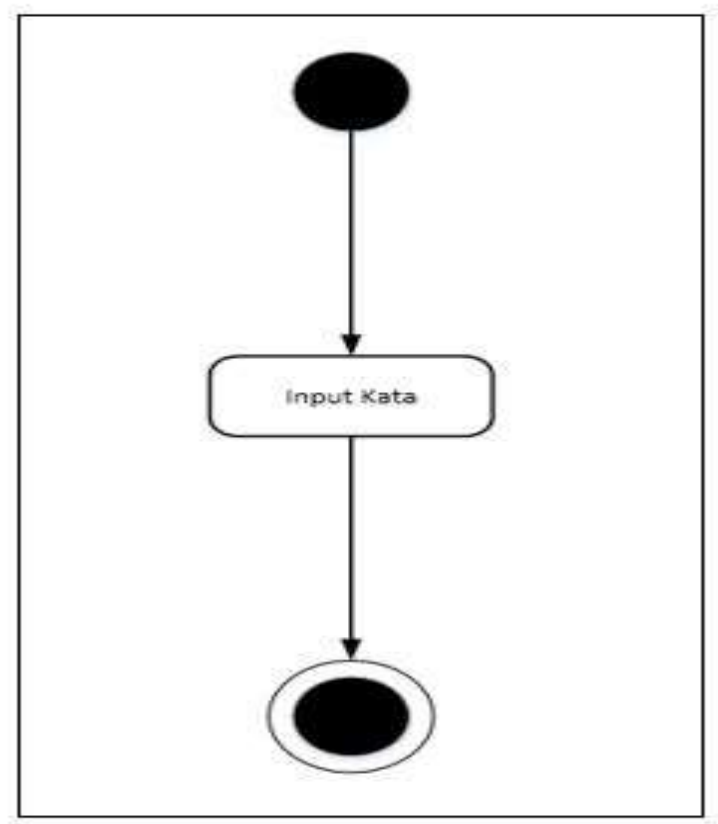

Gambar 4. Gambar activity diagram Input Kata

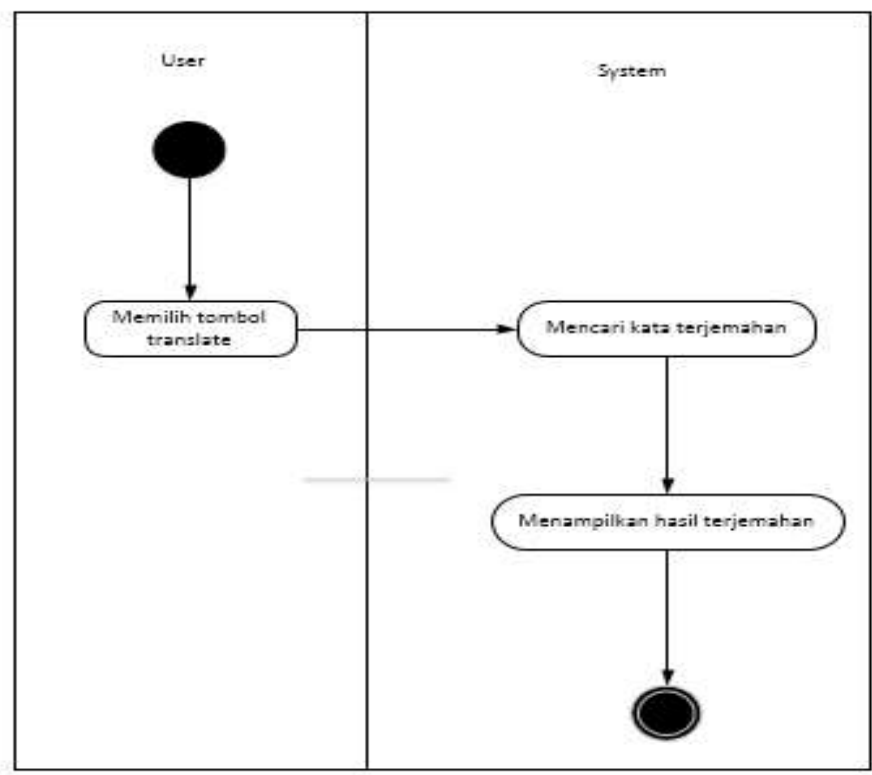

Gambar 5. Gambar activity diagram- translate 


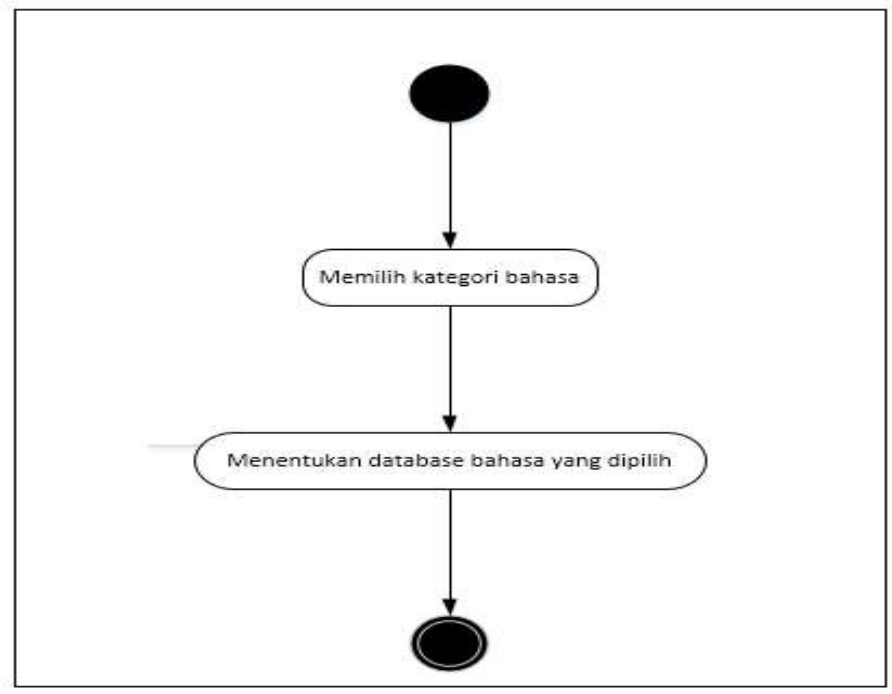

Gambar 6. State Diagram pilih kategori

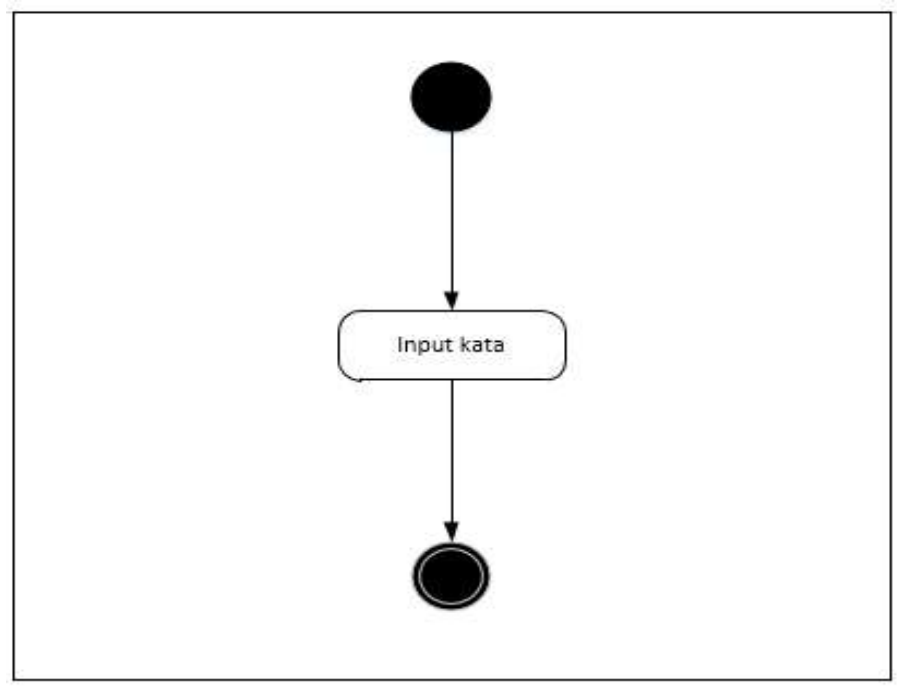

Gambar 7. state diagram Input Kata

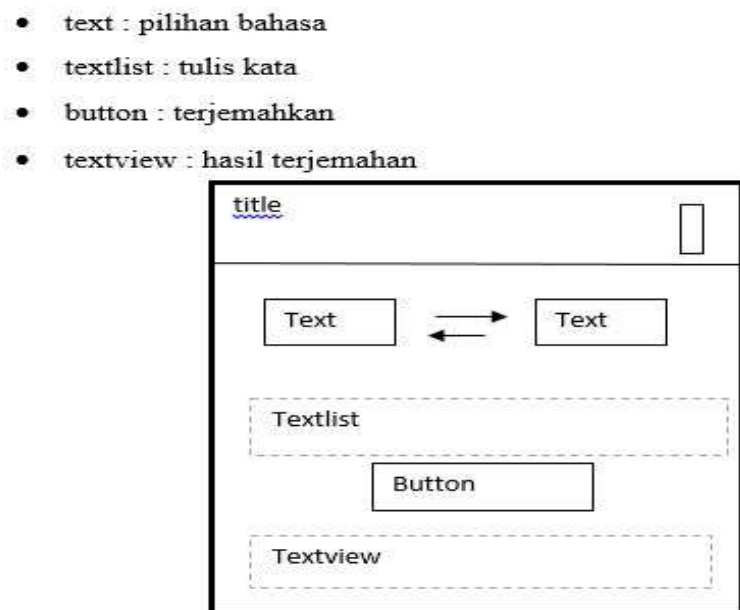

Gambar 8. Tampilan Menu Utama Aplikasi

\section{F. Fase Desain Modeling}

Fase ini memodelkan kembali use case untuk merefleksikan lingkup implementasi. Selain itu untuk memberikan spesifikasi yang jelas dan lengkap kepada programmer.

1) Tabel 1 menunjukkanaplikasi Kamus Bahasa Daerah Pasan berbasis Android ini hanya terdapat satu aktor saja yaitu pengguna atau user. Pengguna dapat melihat data dan mencari kata dari bahasa Indonesia ke Pasan atau sebaliknya.

2) Gambar 1 Tahapan ini merupakan kerangka kerja berupa langka-langka dalam pelaksanaan penelitian. Kerangka kerja yang digunakan menggunakan Metodologi RAD (Rappid Application Development ).

3) Gambar 2 menunjukkan usecase diagram user.

4) Gambar 3 menunjukkan activity diagram-pilih kategor

5) Gambar 4 menunjukkan activity diagram Input Kata

6) Gambar 5 menunjukkan activity diagram-translate

7) Gambar 6 menunjukkan state activity diagram pilih kategori

8) Gambar 7 menunjukkan state diagram input kata

9) Gambar 8 menunjukkan tampilan utama pada aplikasi.

\section{G. Desain Antarmuka}

Pada tahap ini merupakan tahap perancangan antarmuka sebelum aplikasi dibuat.Adapun perancangan tampilan ini akan menampilkan rancangan dari awal eksekusi hingga hasil yang dicari. Beberapa rancangan tampilan antarmuka yang digunakan dalam skripsi, pada gambar 8 .

\section{HASIL DANPEMBAHASAN}

\section{A. Fase Konstruksi}

Pada tahap ini merupakan tahap perancangan antarmuka sebelum aplikasi dibuat. Adapun perancangan tampilan ini akan menampilkan rancangan dari awal eksekusi hingga hasil yang dicari

\section{1) Lingkungan Implementasi}

Tahap ini menunjukkan platform hardware, dan software yang digunakan serta batasan dalam implementasi serta menguji performasi prototype perangkat lunak yang telah dibangun agar dapat diketahui apakah prototype tersebut telah sesuai dengan spesifikasi analisis dan perancangan yang telah diidentifikasi sebelumnya. Tahap ini akan menjelaskan tentang spesifikasi perangkat lunak dan perangkat keras yang digunakan serta batasan implementasi. Dapat dilihat pada tabel 2 dan 3.

\section{B. Implementasi Antarmuka}

1) Gambar 9 menunjukkan proses dimana aplikasi Kamus Bahasa Daerah Ratahan (Pasan) akan diinstal di Smarthphone Android, tampilan tersebut menjelaskan dimana sistem di smartphone kita mengeluarkan perintah Batal atau Pasang.

2) Gambar 10 menunjukkan Aplikasi masuk dalam menu smartphone android 
TABEL II. SPESIFIKASI LAPTOP

\begin{tabular}{ll}
\hline \hline \multicolumn{1}{c}{ Nama } & \multicolumn{1}{c}{ Spesifikasi } \\
Processor & Intel ${ }^{\circledR}$ Celeron 2957U @ \\
& $1,40 \mathrm{GHz}$ \\
RAM & $2 \mathrm{~GB}$ \\
Hard disk & $500 \mathrm{~GB}$ \\
Monitor & 14 inch \\
\hline \hline
\end{tabular}

TABEL III. SPESIFIKASI SMARTPHONE

\begin{tabular}{ll}
\hline \hline Nama & \multicolumn{1}{c}{ Spesifikasi } \\
Processor & Quad-Core 1,4GHz \\
RAM & $1,5 \mathrm{~GB}$ \\
Sistem Operasi & Android Os, 6.0.1 \\
Layar & TFT LCD, display touch and \\
& $\begin{array}{l}\text { display multitouch, Resolusi } \\
540 \times 960(\mathrm{qHD})\end{array}$ \\
\hline
\end{tabular}

Gambar 9. Aplikasi masuk dan siap untuk diinstal

\section{.II等自}

00:46 $82 \%$ 피

Kamus Ratahan Indonesia

\section{Apakah Anda ingin memasang} aplikasi ini? Aplikasi tidak memerlukan akses khusus apa pun.

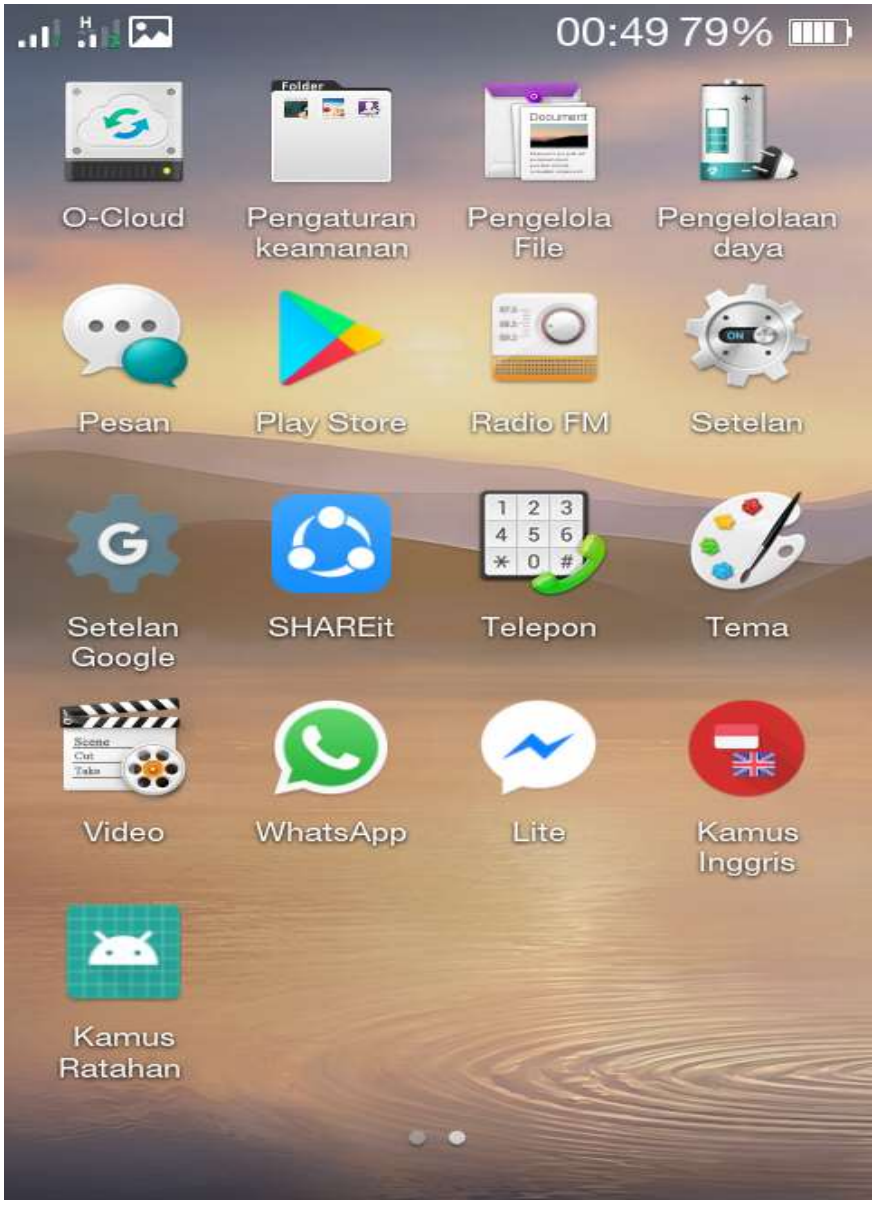

Gambar 10. Aplikasi masuk dalam menu smartphone android .11 等目田 00:50 $78 \%$ 핀

Kamus Ratahan Indonesia

\section{Pasang}

3) Gambar 10 menunjukkan tampilan menu utama dari Aplikasi Kamus Bahasa Daerah Ratahan (Pasan) yang diakses oleh user saat menjalankan aplikasi ini. Pada menu utama user dapat memasukan sebuah kata yang akan dicari terjemahannya.

\section{Batal}

Gambar 11. Tampilan Menu Utama 


\section{PENUTUP}

\section{A. Kesimpulan}

Setelah melakukan penelitian ini, dapat ditarik kesimpulan bahwa Aplikasi Kamus Bahasa Daerah Ratahan (Pasan) telah berhasil dibangun dan dapat menjadi sarana untuk mempermudah masyarakat dalam mempelajari dan melestarikan bahasa Pasan. Aplikasi ini juga dibuat sesederhana mungkin agar dapat membantu siapa saja yang ingin belajar dan lebih memahami bahasa Ratahan dalam mencari kata-kata lebih cepat dan mudah melalui smarthphone.

\section{B. Saran}

Untuk pengembangan sistem informasi pemetaan ini maka penulis memberikan saran sebagai berikut :

1) Pengembagan sistem innformasi terlebih khusus aplikasi sistem informasi ini bisa ditambahkan lagi jarak lokasi user ke rumah ibadah yang dipilih dapat memudahkan user mengakses.

2) Data dan informasi pada sistem informasi lebih akurat berasal dari dinas terkait.

3) Pengembangan aplikasi sitem informasi terutama untuk fitur-fitur bisa lagi di kembangkan dan di perhatikan agar user lebih mudah dan puas menggunakan aplikasi Sistem Informasi Pemetaan Rumah Ibadah di Kota Tomohon.

\section{KUTIPAN}

[1] Ir. Balza Achmad, M.Sc.E. 2006. Diktat Mata Kuliah Kecerdasan Buatan.Jurusan Teknik Fisika Fakultas Teknik Universitas Gadjah Mada, Yogyakarta

[2] Jenny Purba, Gisela Sevani, Cynthia Hayat. Aplikasi Diagnosa Dini Penyakit Kanker Payudara. Fakultas Teknik dan dan Ilmu Komputer Jurusan Teknik Informatika Universitas Kristen Krida Wacana, Jakarta

[3] Sari, N.A . 2013. Sistem Pakar Diagnosa Penyakit Demam Berdarah Menggunakan Metode Certainty Factor. Program Studi Teknik Informatika STMIK Budidarma. Medan

[4] Andini, A. and Dea, P. Sistem Pakar Diagnosa Penyakit Kanker Payudara Menggunakan Certainty Factor. Jurusan Sistem Informasi STMIK PALCOMTECH. Palembang

[5] Kus Anna, L. Deteksi Dini, Jawaban untuk Menghindari Kanker Payudara. http://health.kompas.com, 30 September 2015.

[6] Hakim, Z. Implementasi Metode RAD Dalam Pengembangan Sistem Kepegawaian. Fakultas Ilmu Komputer Universitas Bina Darma. Palembang 